\title{
Avaliação da atividade antimicrobiana de extratos vegetais
}

\author{
D.C. Michelin ${ }^{1}$, P.E. Moreschi', A.C. Lima', G.G.F. Nascimento ${ }^{3}$, M.O. Paganelli', \\ M.V. Chaud ${ }^{3 *}$
}

${ }^{1}$ Departamento de Fármacos e Medicamentos, Faculdade de Ciências Farmacêuticas, Universidade Estadual Paulista "Júlio de Mesquita Filho" - UNESP, Rodovia Araraquara - Jaú, Km 1, 14801-902, Araraquara, SP, Brasil,

${ }^{2}$ Departamento de Fármacos e Medicamentos, Faculdade de Ciências Farmacêuticas de Ribeirão Preto - USP, Rodovia do Café, S/N, 15500-816, Ribeirão Preto, SP, Brasil,

${ }^{3}$ Faculdade de Ciências da Saúde, Curso de Farmácia, Universidade Metodista de Piracicaba - UNIMEP, Rodovia do Açúcar, Km 157, 13400-911, Piracicaba, SP, Brasil

\begin{abstract}
RESUMO: Especialmente nas últimas décadas, inúmeros esforços têm sido dirigidos para conferir às plantas seu real papel e valor na terapia. Neste estudo foi avaliada a atividade antimicrobiana de extratos secos de Artemisia absinthium L. (losna), Mentha pulegium L. (poejo), Punica granatum L. (romã), Xanthosema violaceum Schott (taioba) e Syzygium cuminii L. (jambolão). Para avaliar a atividade antimicrobiana foi realizado o teste de difusão em ágar, com 15 diferentes microrganismos, utilizando discos impregnados com as dispersões aquosas dos extratos vegetais. A Concentração Inibitória Mínima (CIM) foi determinada para os extratos que apresentaram atividade inibitória. Os resultados mostraram que os extratos de $X$. violaceum e $S$. cuminii inibiram, respectivamente, 8 e 6 bactérias. Conclui-se que os extratos de $X$. violaceum e $S$. cuminii são capazes de inibir expressivamente o crescimento microbiano.
\end{abstract}

Unitermos: Artemisia absinthium, Mentha pulegium, Punica granatum, Syzygium cuminii, Xanthosema violaceum, atividade antimicrobiana.

\begin{abstract}
Evaluation of the antimicrobial activity of vegetal extracts". In the last decades, innumerable efforts have been directed to confer to the plants its real value in the therapy. The aim of this study was to evaluate the antimicrobial activity of dry extracts of Artemisia absinthium L. (wormwood), Mentha pulegium L. (poejo), Punica granatum L. (pomegranate), Xanthosema violaceum Schott (taro) and Syzygium cuminii L. (jambolan). To evaluate the antimicrobial activity the diffusion test in agar was carried through, with 15 different microorganisms, using discs impregnated with aqueous dispersions of the vegetal extracts. For those extracts that had presented inhibitory activity, the calculation of Minimum Inhibitory Concentration was carried out (CIM). The results had shown that the extracts of X. violaceum and S. cuminii had inhibited 8 and 6 bacteria, respectively. What leads to the conclusion that the extracts of $X$. violaceum and $S$. cuminii are capable to inhibit the microbial growth.
\end{abstract}

Keywords: Artemisia absinthium, Mentha pulegium, Punica granatum, Syzygium cuminii, Xanthosema violaceum, antimicrobial activity.

\section{INTRODUÇÃO}

Nos países em desenvolvimento as doenças estão relacionadas com a falta de saneamento básico, desnutrição e dificuldade de acesso aos medicamentos (Kumate, 1997). Neste contexto e decorrente do uso etnomedicinal, a fitoterapia é amplamente praticada. Entre as plantas medicinais mais utilizadas pela população poucas têm ação comprovada. Contudo, o uso popular tradicionalmente consolidado tem sido utilizado como guia para pesquisas farmacológicas (Elisabetsky, 1987; Babu et al., 1997).

Diversos vegetais têm sido utilizados com fins profiláticos e curativos de infecções, entre eles encontramse aqueles que são objetos deste estudo. Atualmente muitos trabalhos vêm sendo realizados em busca de novas plantas com atividade antimicrobiana. Machado et al. (2003) avaliaram 14 extratos de plantas medicinais brasileiras, utilizadas no tratamento de doenças infecciosas, quanto ao seu potencial antimicrobiano frente a microrganismos resistentes de importância médica. O extrato de Punica granatum L. (romã) mostrou-se eficiente contra Staphylococcus aureus resistente a meticilina. O óleo essencial de Artemisia annua L. foi avaliado quanto a sua atividade antimicrobiana e inibiu o crescimento de uma bactéria Gram positiva Enterococcus hirae e dos fungos testados (Juteau et al., 2002). O óleo essencial das folhas de $S$. cuminii e Syzygium travancoricum Gamble foram testados para avaliar suas propriedades antibacterianas. A atividade do óleo essencial de $S$. cuminii foi considerada 
boa, enquanto do $S$. travancoricum foi moderada (Holetz et al., 2002).

A atividade antimicrobiana de extrato metanólico de Artemisia afra Jacq sobre várias bactérias Gram positivas e fungos foi observada por Rabe e Van Staden (1997). Kalemba et al. (2002) observaram boa atividade antimicrobiana de óleos essenciais obtidos de Artemisia asiatica Nakai, especialmente a fração de monoterpenos, e seus principais constituintes contra bactérias e fungos. Ação antibacteriana também foi observada nas frações flavonoídicas obtidas do extrato de $A$. annua sobre $S$. aureus resistente a antibióticos. Stermitz et al. (2002) observaram ainda ação sinérgica destas substâncias com berberina (alcalóide) e norfloxacino (antibiótico) as quais, individualmente, não inibiam as bactérias resistentes. Alzoriky e Nakahara (2003), estudando a ação de extrato de $A$. absinthium sobre as bactérias $S$. aureus, Bacillus cereus, Listeria, Salmonella e Escherichia coli, observaram MIC variando entre 165 a $2640 \mathrm{mg} / \mathrm{mL}$.

A ação antimicrobiana de óleos essenciais de Mentha suaveolens Ehrh. sobre bactérias Gram positivas e negativas e fungos, foi verificada por Oumzil et al. (2000). Dentre os constituintes aromáticos, o pulegona, foi o que apresentou ação mais potente. Imai et al. (2001) testando a atividade antimicrobiana de óleos essenciais de Mentha piperita L. e Mentha arvensis L., verificaram ação contra as bactérias Helicobacter pylori e $S$. aureus, tanto linhagens sensíveis como resistentes a antibióticos.

Perez e Anesini (1994) verificaram a ação inibitória de P. granatum sobre a Salmonella typhi. A ação inibitória de extratos desta planta também foi observada por Prashant et al. (2001) e Pessini et al. (2003) sobre várias bactérias e fungos. Holetz et al. (2002), estudando a ação de vários extratos de plantas brasileiras, observaram que $P$. granatum apresentou boa atividade contra $S$. aureus e outras bactérias. Machado et al. (2003) estudando 14 extratos de plantas usadas tradicionalmente no Brasil para tratamento de doenças infecciosas, verificaram que $P$. granatum inibiu linhagens de $S$. aureus sensíveis e resistentes (MRSA) a meticilina, concluindo que estas substâncias apresentam-se potenciais como agentes no tratamento de infecções causadas por MRSA.

A ação antibacteriana de $S$. guineense Willd. contra vários patógenos intestinais como Salmonella, Shigella, E. coli e Enterobacter foi observada por Tsakala et al. (1996). Dorman e Deans (2000) testaram óleos essenciais extraídos de Syzygium, constatando ação antibacteriana sobre patógenos de plantas, animais e espécie humana, especialmente os causadores de infecção alimentar. Resultados semelhantes foram encontrados por Caio e Wu (1996) sobre várias bactérias Gram negativas anaeróbias, causadoras de infecções periodontais. Por outro lado, Burt e Reinder (2003) não observaram efeito inibitório de jambolão sobre $E$. coli $0157: \mathrm{H} 7$.

Djipa et al. (2000) estudando a atividade antimicrobiana de extratos de jambolão sobre vários microrganismos, entre eles, $S$. aureus, verificaram que esta propriedade foi devida à alta concentração de taninos (77 a $83 \%$ ). Isto pôde ser comprovado pelo fato de que não mais se observou esta propriedade, quando os taninos foram suprimidos. A ação sobre vírus foi verificada por Kashiwada et al. (1998) que testaram o ácido oleanólico obtido de jambolão, observando que provocou interferência sobre a replicação do vírus HIV em culturas de células.

Nascimento et. al. (2000), avaliaram a atividade antibacteriana de vários extratos de plantas e fitofármacos sobre bactérias sensíveis e resistentes a antibióticos. Dentre os extratos utilizados estavam os de $P$. granatum e de Syzygium jambolanum Lam., sendo que este último inibiu 57,1\% dos microorganismos testados, muitos dos quais resistentes a antibióticos.

A presente investigação foi realizada para avaliar a atividade antimicrobiana de Artemisia absinthium L. (losna), Mentha pulegium L. (poejo), Punica granatum L. (romã), Xanthosema violaceum Schott (taioba) e Syzygium cuminii L. (jambolão).

\section{MATERIAL E MÉTODOS}

\section{Vegetais}

Folhas de Artemisia absinthium L., Mentha pulegium L., Xanthosema violaceum Schott, Syzygium cuminii L. e cascas de Punica granatum L. foram adquiridas de YOD - Comércio de Produtos Naturais Ltda, no estado seco, acompanhadas de um laudo de identificação.

\section{Microrganismos}

Foram utilizadas cepas padrões de Escherichia coli (ATCC 25922), Pseudomonas aeruginosa (ATCC 27583) e Staphylococcus aureus (ATCC29213), a levedura Candida albicans (ATCC 10.231) e 11 bactérias resistentes a antibióticos isoladas em ambiente hospitalar: S. aureus numeradas como $8,36,68,115 ;$ E. coli $6.2 \mathrm{e}$ 1.9c; Proteus sp 6.3; P. aeruginosa 6.4 e Enterobacter sp $1.17 \mathrm{~b}$.

\section{Preparação dos extratos secos}

Os vegetais foram reduzidos ao estado de pó através de moagem e padronizados com auxílio de tamises de 150 e $75 \mu \mathrm{m}$. Em seguida foram umedecidos com etanol $50 \%$ e deixados em repouso por 24 horas, em recipientes fechados, ao abrigo da luz. Este material foi acomodado em percolador e submetido ao processo de lixiviação com etanol $50 \%$ até o esgotamento total da droga. Antes da liofilização o etanol foi removido com auxílio de evaporador rotativo até $1 / 3$ do volume original.

\section{Avaliação da atividade antimicrobiana}


Tabela 1. Atividade antimicrobiana de extratos vegetais sobre bactérias sensíveis e bactérias resistentes a antibióticos (difusão em ágar).

\begin{tabular}{|c|c|c|c|c|c|}
\hline \multirow{3}{*}{ Bactérias } & \multicolumn{5}{|c|}{ Extratos Vegetais $(\mathrm{mg} / \mathrm{mL})$} \\
\hline & A. absinthium & M. pulegium & $X$. violaceum & S. cuminii & P. granatum \\
\hline & 200 & 200 & 50 & 60 & 100 \\
\hline E. coli ATCC 25922 & + & + & + & - & - \\
\hline P. aeruginosa ATCC 27583 & + & + & - & + & - \\
\hline S. aureus ATCC 29213 & + & - & - & - & + \\
\hline E. coli 6.2 & + & + & - & - & - \\
\hline E. coli $1.9 \mathrm{c}$ & + & + & - & - & - \\
\hline Proteus sp 6.3 & + & + & - & - & + \\
\hline P. aeruginosa 6.4 & + & + & + & + & - \\
\hline Enterobacter sp $1.17 \mathrm{~b}$ & + & + & + & + & - \\
\hline S. aureus $\mathrm{OX}^{8}$ & + & + & - & - & + \\
\hline S. aureus $\mathrm{OX}^{18}$ & + & + & + & + & + \\
\hline S. aureus $\mathrm{OX}^{36}$ & + & + & - & + & + \\
\hline S. aureus $\mathrm{OX}^{68}$ & + & + & + & + & + \\
\hline S. aureus $\mathrm{OX}^{115}$ & + & + & - & + & + \\
\hline S. aureus $\mathrm{OX}^{134}$ & + & + & + & + & + \\
\hline Candida albicans & + & + & + & + & + \\
\hline
\end{tabular}

(-) Inibição; (+) Crescimento

OX - Oxacilina resistente

Para a análise microbiológica, culturas bacterianas desenvolvidas em BHI por 24 horas foram diluídas convenientemente (cerca de $10^{8} \mathrm{UFC} / \mathrm{mL}$ ) e semeadas na superfície de ágar Mueller-Hinton. A seguir, discos de papel de filtro impregnados com os extratos vegetais a serem testados foram colocados sobre a superfície do ágar inoculado. Após incubação por 48 horas a $37^{\circ} \mathrm{C}$, foram observados os halos de inibição das amostras bacterianas. Os solventes bem como os diluentes utilizados na dissolução dos extratos foram usados como controle negativo (NCCLS, 2000).

\section{Determinação da Concentração Inibitória Mínima - CIM}

Os extratos vegetais que apresentaram atividade antimicrobiana foram ensaiados para determinação da CIM para cada uma das espécies bacterianas (Lorian, 1996). Para isso, culturas bacterianas desenvolvidas em caldo nutriente por 6 horas, e diluídas convenientemente (cerca de $10^{6} \mathrm{UFC} / \mathrm{mL}$ ) foram inoculadas em tubos contendo caldo nutriente acrescido de diferentes concentrações dos extratos. Após incubação de 48 horas a $37^{\circ} \mathrm{C}$ foi observada a ocorrência de turvação dos caldos de

Tabela 2. Concentração Inibitória Mínima (CIM) de extratos vegetais sobre bactérias padrões e resistentes a antibióticos.

\begin{tabular}{|c|c|c|c|}
\hline \multirow[t]{2}{*}{ Bactérias } & \multicolumn{3}{|c|}{ Extratos vegetais $(\mathrm{mg} / \mathrm{mL})$} \\
\hline & $X$. violaceum & S. cuminii & P. granatum \\
\hline E. coli ATCC 25922 & - & - & 25 \\
\hline P. aeruginosa ATCC 27583 & - & - & - \\
\hline S. aureus ATCC 29213 & - & - & - \\
\hline E. coli 6.2 & 140 & - & - \\
\hline E. coli $1.9 \mathrm{c}$ & - & $160-180$ & - \\
\hline Proteus sp 6.3 & 140 & 120 & - \\
\hline P. aeruginosa 6.4 & - & - & 40 \\
\hline Enterobacter sp $1.17 \mathrm{~b}$ & - & - & - \\
\hline S. aureus $\mathrm{OX}^{8}$ & 140 & $160-180$ & - \\
\hline S. aureus $\mathrm{OX}^{18}$ & - & - & - \\
\hline S. aureus $\mathrm{OX}^{36}$ & - & - & - \\
\hline S. aureus $\mathrm{OX}^{68}$ & - & - & - \\
\hline S. aureus $\mathrm{OX}^{115}$ & 150 & - & - \\
\hline S. aureus $\mathrm{OX}^{134}$ & - & 150 & - \\
\hline
\end{tabular}




\section{Atividade antimicrobiana de extratos vegetais}

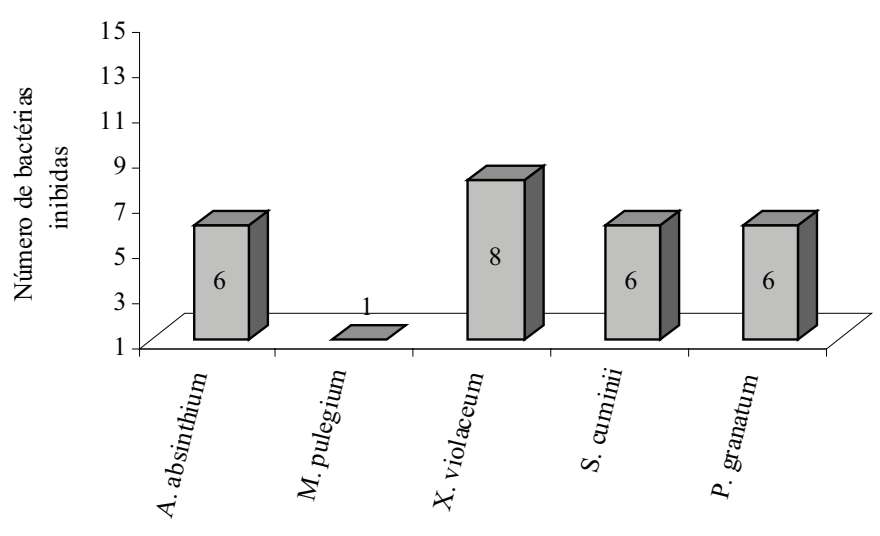

Extratos vegetais

Figura 1: Atividade antimicrobiana dos extratos vegetais.

culturas para determinação da CIM (menor concentração capaz de inibir o crescimento de microrganismos).

\section{RESULTADOS}

Os extratos secos obtidos de $A$. absinthium, M. pulegium, $P$. granatum, $S$. cuminii e $X$. violaceum apresentaram rendimento de 4,85, 3,78, 12,40, 14,38 e $13,49 \%$, respectivamente.

As Tabelas 1 e 2 mostram respectivamente a atividade antimicrobiana sobre bactérias sensíveis e bactérias resistentes a antibióticos e a CIM dos extratos vegetais sobre bactérias padrões e resistentes a antibióticos. A atividade antimicrobiana dos vegetais sobre cepas padrões e resistentes está representada na Figura 1.

\section{DISCUSSÃO}

A remoção do etanol evitou que sua atividade bacteriostática mascarasse propriedades antimicrobianas do extrato vegetal. Tanto a remoção do etanol como a redução do volume de água antes da liofilização foi feita em condições brandas de temperatura para evitar degradação de substâncias termolábeis presentes no extrato fluido.

$\mathrm{Na}$ Tabela 1, estão apresentados os resultados da atividade antimicrobiana de extratos vegetais sobre microrganismos. Observa-se que a levedura C. albicans não foi inibida por nenhum dos extratos. Os extratos de A. absinthium e $M$. pulegium apresentaram pouca ou nenhuma atividade antimicrobiana até a concentração de $200 \mathrm{mg} / \mathrm{mL}$.

Extratos com atividade mais expressiva foram os de $X$. violaceum, $P$. granatum e $S$. cuminii que inibiram, respectivamente, 53,3, 40,0 e 40,0\% dos microrganismos testados (Figura 1). Deve ser ressaltado que $X$. violaceum e S. cuminii nas concentrações de 50 e 60 $\mathrm{mg} / \mathrm{mL}$, respectivamente, inibiram tanto bactérias Gram positivas quanto Gram negativas, porém $P$. granatum, na concentração de $100 \mathrm{mg} / \mathrm{mL}$ inibiu apenas bactérias Gram negativas.

A CIM foi determinada para extratos que apresentaram atividade antimicrobiana (Tabela 2). Observa-se que o CIM dos extratos de $X$. violaceum e S. cuminii variou entre 120 e $180 \mathrm{mg} / \mathrm{mL}$. O extrato de P. granatum mostrou ser mais eficaz, apresentando CIM entre 25 e $40 \mathrm{mg} / \mathrm{mL}$, o que não ocorreu quando se utilizou a técnica de difusão em ágar, onde a atividade inibitória ocorreu em concentrações mais elevadas. Atividade semelhante da $P$. granatum também foi observada por outros autores sobre vários tipos de microrganismo (Peres e Anesini, 1994; Holetz et al., 2002). A atividade antimicrobiana do $S$. cuminii também foi observada por outros autores (Djipa et al., 2000; Dorman; Deans, 2000). Djipa et al., 2000 sugerem que a atividade antimicrobiana está relacionada com a alta quantidade de taninos, já que a eliminação destes suprimiu esta propriedade. Nascimento et al., 2000, verificaram que extrato de $S$. cuminii inibiu $57,1 \%$ das bactérias testadas, muitas das quais resistentes a antibióticos, com CIM variando entre 50 a $400 \mu \mathrm{L} /$ mL. Da mesma forma, Machado et al., 2003 também observaram efeito inibitório sobre bactérias $S$. aureus resistente a oxacilina.

Os resultados confirmam o uso etnomedicinal com finalidade antimicrobiana destas plantas. Os extratos vegetais testados apresentam atividade antimicrobiana para microrganismos de cepas padrões e resistentes. Embora tenhamos encontrado efeito inibitório para microrganismos resistentes $\left(S\right.$. aureus $O X^{8}, S$. aureus $\mathrm{OX}$ ${ }^{36}, S$. aureus $O X^{115}$ ), no geral esta atividade foi limitada. Embora os resultados obtidos neste estudo suportem o 
uso fitoterápico destes vegetais não recomendamos, sem estudos mais aprofundados, o uso popular destas plantas no combate a infecções severas.

\section{REFERÊNCIAS}

Alzoriky NS, Nakahara K 2003. Antibacterial activity of extracts from some plants commonly consumed in Asia. Int J Food Microbiol 80: .223-230.

Babu SPS, SarkarD, Ghosh NK, Saha A, Sukul NC, Bhattacharya S 1997. Enhancement of membrane damage by saponins isolated from Acacia auriculiformis. Jpn J Pharmacol 75: 451-454.

Burt SA, Reinder RD 2003. Antibacterial activity of selected plant essential oils against Escherichia coli 0157: H7. Lett Appl Microbiol 36:162-167.

Caio L, Wu CD 1996. Compounds from Syzygium aromaticum possessing growth inhibitory activity against oral pathogens. J Nat Prod 59: 987-990.

Djipa CD, Delmee M, Quentin-Leclercq J 2000. Antimicrobial Activity of bark extracts of Syzygium jambos (Myrtaceae). J Ethnopharmacol 71:307-313.

Dorman HJD, Deans SG 2000. Antimicrobial agents from plants: antibacterial activity of plant volatile oils. $J$ Appl Microbiol 88: 308-316.

Elisabetsky E 1987. Pesquisa em plantas medicinais. Ciências e Cultura 39: 607-702.

Holetz FB, Pessini GL, Sanches NR, Cortez DA, Nakamura CV 2002. Screening of some plants used in the Brazilian folk medicine for the treayment of infectious diseases. Mem I Oswaldo Cruz 97: 1027-1031.

Imai H, Osaka K, Yasuda H, Hamashira H, Arai T 2001. Inhibition by the essential oils of peppmint and spearmint on the growth of pathogenic bacteria. Microbios 106: 31-39.

Juteau F, Masotti V, Bessiere JM, Dherbomez M, Viano J 2002 Antibacterial and antioxidant activities of Artemisis annua essential oil. Fitoterapia 73: 532-535.

Kalemba D, Kusewicz D, Swiader K 2002. Antimicrobial properties of the essential of Artemisia asiatica nakai. Phytother Res 16: 288-291.

Kashiwada Y, Wang HK, Nagao T, Kitanasaka S, Yasuda I, Fujioka T, YAmagishi T, Cosentino LM, Kosuka M 1998. Anti HIV activity of oleanolic acid, pomolic acid and structurally related triterpenoids. $J$ Nat Prod 61: 1090-1095.

Kumate J 1997. Infectious disease in the $21^{\text {st }}$ century. Arch Med Res 28: 155-161.

Lorian J 1996. Antibiotics in laboratory medicine. Baltimore, EUA: Ed. William \& Wilkin.

Machado TB, Pinto AV, Pinto MCFR, Leal ICR, Silva MG, Amara CF, Kuster LRM, Neto KR 2003. In vitro activity of Brasilian medicinal plants, naturally ocorring naphthoquinones and their analougues, against methicilin-resistant Staphylococcus aureus. Int J Antimicrob Ag 21: 279-284.

Nascimento GGF, Locatelli J, Freitas PCD, Silva GL 2000. Antibacterial activity of plant extract and phytochemicals on antibiotic-resistant bacteria. Braz J Microbiol 31: 247-256.

NCCLS (National Committee for Clinical Laboratory Standards), 2000.
Oumzil H, Ghoulami S, Rhajaoui M, Ilidrissi A, Tetouami S, Faid M, Benjouad A 2000. Antibacterial and antifungal activity of essencial oils of Mentha suaveolens. Phytother Res 16: 727-731.

Perez C, Anesini C 1994. In vitro antibacterial activity of Argentinr folk medicinal olants against Salmonella typhi. J Ethnopharmacol 44: 41-46.

Pessini GL, Holetz FB, Sanches NR, Cortez DAG, Dias-Filho BP, Nakamura CV 2003. Avaliação da atividade antibacteriana e antifúngica de extratos de plantas utilizados na medicina popular. Rev Bras Farmacogn 13(Supl 1): 21-24.

Prashant D, Asha MK, Amit A 2001. Antibacterial activity of Punica granatum. Fitoterapia 72: 171-173.

Rabe T, Van Sataden J 1997. Antibacterial activity of $S$. cuminii and $S$. travancoricum leaf essential oils. Fitoterapia 73: 414-416.

Stermitz FR, Scriven LN, Tegos,G, Lewis K 2002. Two flavonols from Artemisia annua wich potentiate the activity of berberine and norfloxacin against a resistant strains of Staphylococcus aureus. Planta Med 68: 1140-1141.

Tsakala TM, Penge O, Jonh K 1996. Screening of in vitro antibacterial activity from Syzygium guineense (Willd) hydro soluble dry extract. Ann Pharm Fr 54: 276-279. 